\title{
MLANA Positive
}

National Cancer Institute

\section{Source}

National Cancer Institute. MLANA Positive. NCI Thesaurus. Code C134491.

An indication that MLANA expression has been detected in a sample. 